\title{
CEMENTLESS REVISION OF AGGRESSIVE GRANULOMATOUS LESIONS IN HIP REPLACEMENTS
}

\author{
A. ESKOLA, S. SANTAVIRTA, Y.T. KONTTINEN, V. HOIKKA, K. TALLROTH, T. S. LINDHOLM
}

From the Orthopaedic Hospital of the Invalid Foundation, Helsinki

\begin{abstract}
In 16 patients we used uncemented Lord prostheses at revision operations for aggressive granulomatosis after cemented hip arthroplasties; in 12 bone grafts also were used. In 13 hips the granulomatous lesions were multifocal, and in one the acetabular component was involved. There was no evidence of infection in any case: all the patients had normal ESR and CRP levels.

The revision operation was performed on average 9.4 years after the primary replacement; the mean age at revision was 64 years. On radiographs, the bone around the prosthesis had consolidated by an average of 16 months. At follow-up, two to six years later (mean 3.5 years) there had been no recurrences, nine patients had an excellent Mayo hip score, five were good and two fair.
\end{abstract}

Aggressive granulomatosis after total hip arthroplasty was first described in four patients by Harris et al (1976). They defined it as a benign, non-inflammatory, tissue reaction which caused extensive, localised, tumour-like resorption around the cemented femoral component. Since then the clinical characteristics and histopathological appearance of these lesions have been described in small numbers of patients (Bell et al 1983; Goldring et al 1983; Reinus et al 1985; Scott, Riley and Dorfman 1985; Griffiths, Burke and Bonfiglio 1987). It has become evident that aggressive granulomatosis differs from the usual prosthetic loosening. Histopathologically these granulomas are characterised by a large number of histiocytes (Goldring et al 1983; Tallroth et al 1989).

Aggressive granulomatosis is not as rare as previously thought : nearly $5 \%$ of our total hip revisions are for these lesions (Tallroth et al 1989). Little has been published about revision operations for this condition.

A. Eskola, MD, Research Fellow

S. Santavirta, MD, PhD, Consultant Surgeon

V. Hoikka, MD, PhD, Research Fellow

K. Tallroth, MD, PhD, Senior Radiologist

T. S. Lindholm, MD, PhD, Professor

The Orthopaedic Hospital of the Invalid Foundation, Tenholantie 10, 00280 Helsinki 28, Finland.

Y. T. Konttinen, MD, PhD, Assistant Professor

The Fourth Department of Medicine, University Central Hospital, Unioninkatu 38, 00170 Helsinki 17, Finland.

Correspondence should be sent to Dr S. Santavirta at W. Aaltosentie 9, SF-00570 Helsinki 57, Finland.

(C) 1990 British Editorial Society of Bone and Joint Surgery

$0301-620 \mathrm{X} / 90 / 2058 \$ 2.00$

J Bone Joint Surg [Br] 1990; 72-B : 212-6.
Revision with a new cemented arthroplasty is usually successful, but, in our experience, there is a risk of recurrence. Hoping to reduce this risk we have begun to use an uncemented prosthesis, usually with bone grafting. We have analysed this experience and now report our results.

\section{PATIENTS AND METHODS}

We report 16 patients having total hip revision with an uncemented Lord prosthesis for aggressive granulomatosis, treated at the Orthopaedic Hospital of the Invalid Foundation, Helsinki, from 1983 to 1986 . We defined aggressive granulomatosis as a condition which, in the definite absence of infection, showed large ovoid lytic areas whose shape did not correspond to that of the prosthesis-cement complex. They sometimes appeared to grow rapidly (Figs 1 and 2) (Tallroth et al 1989).

There were 13 men and three women, with an average age of 55 years (33 to 78$)$ at the time of the primary hip replacement. Thirteen had had this replacement for primary osteoarthritis, one for old tuberculosis (Figs 3 and 4), one for femoral neck fracture and one due to congenital acetabular dysplasia (Table I). At the primary operation, eight Brunswik prostheses, three Lubinus, two McKee-Farrar, and one each of Christiansen, Legrange-Letournel and Austin-Moore type had been implanted.

All 16 patients complained of local pain on stress as the first clinical sign, beginning on average 7.8 years $(2.0$ to 12.5) after the primary arthroplasty.

The granulomatous lesions were multifocal in 13 
Case 3. Figure 1 - A 59-year-old man 11 years after a Brunswik total hip replacement. There are multiple aggressive granulomas (arrows). Figure 2 - Four years after an uncemented revision with a Lord prosthesis the result is satisfactory.

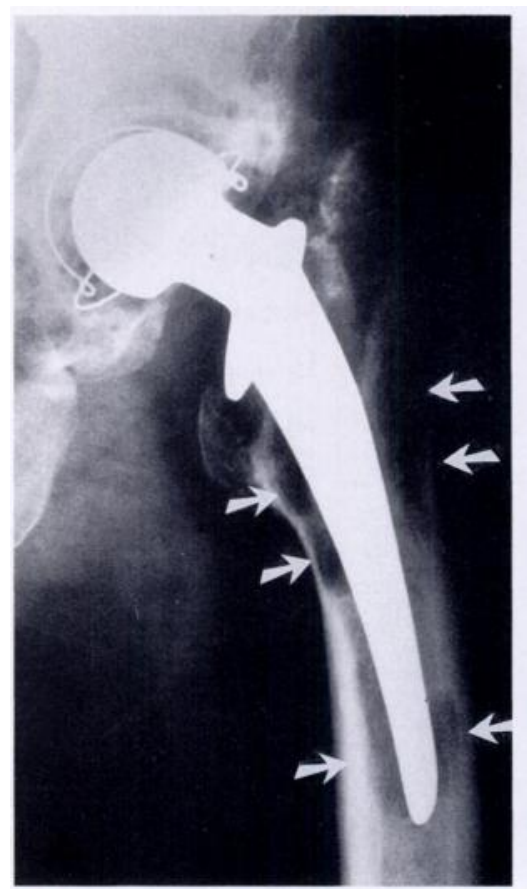

Fig. 1

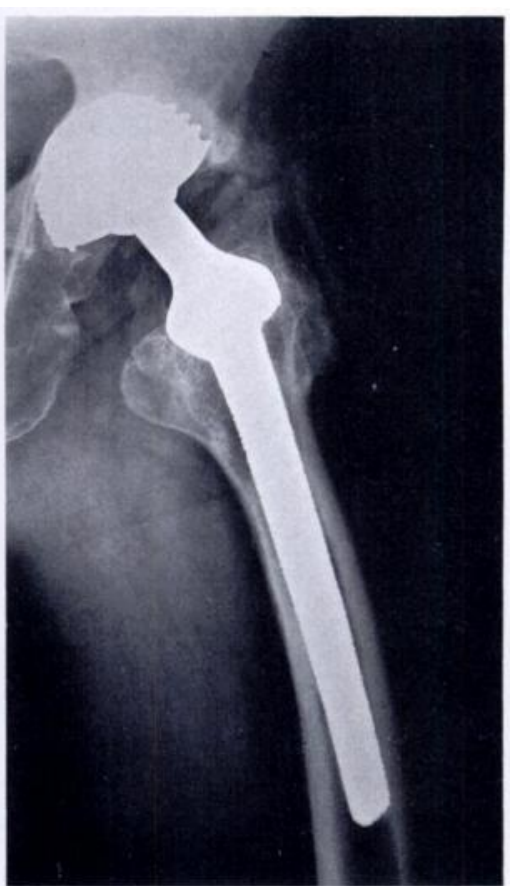

Fig. 2

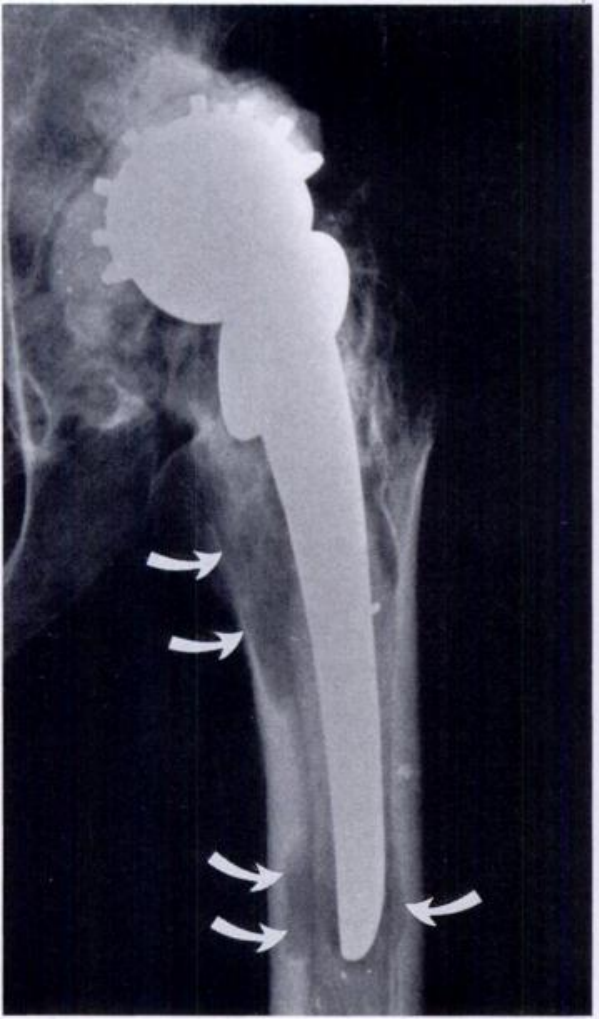

Fig. 3

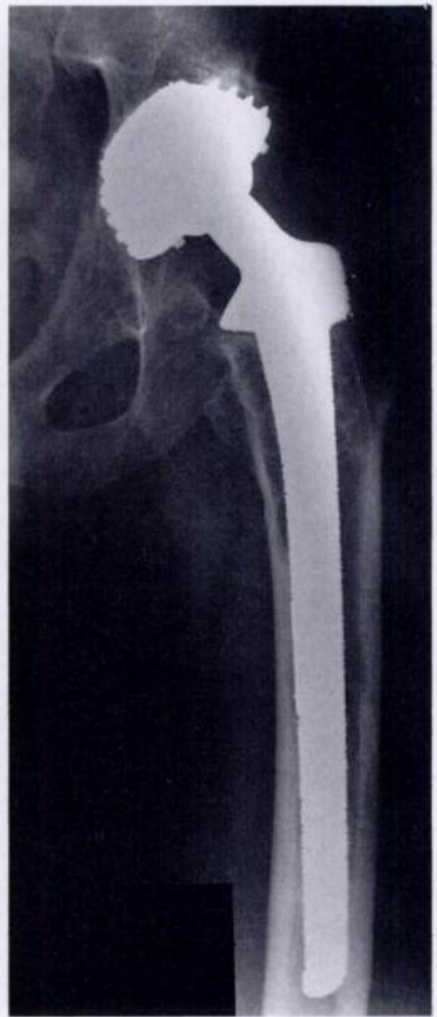

Fig. 4

Case 6. Figure 3 - This man had tuberculous arthritis of the hip in early childhood leading to fusion. At the age of 33 years the arthrodesis was converted to a McKee-Farrar total hip replacement. Ten years later there are multiple aggressive granulomas (arrows). Figure 4 - Four years after uncemented revision and cancellous bone grafting, the prosthesis is well incorporated and there are no signs of recurrence. 
Table I. Details of 16 patients with aggressive granulomatosis after cemented hip arthroplasty

\begin{tabular}{|c|c|c|c|c|c|c|c|}
\hline Case & $\begin{array}{l}\text { Age at primary } \\
\text { arthroplasty (yr) }\end{array}$ & Sex & Side & Granuloma & $\begin{array}{l}\text { Sinking of } \\
\text { femoral } \\
\text { stem (mm) }\end{array}$ & $\begin{array}{l}\text { Onset of pain after } \\
\text { primary arthroplasty } \\
\text { (yr) }\end{array}$ & Primary prosthesis \\
\hline 1 & 66 & $\mathbf{M}$ & $\mathbf{R}$ & Multiple & 0 & 5.5 & Christiansen \\
\hline 2 & 46 & $\mathbf{M}$ & L & Multiple & 3 & 8.5 & Brunswik \\
\hline 3 & 59 & $\mathbf{M}$ & L & Multiple & 6 & 7.0 & Brunswik \\
\hline 4 & 59 & $\mathbf{M}$ & L & Multiple & 6 & 11.5 & Brunswik \\
\hline 5 & 58 & $\mathbf{M}$ & $\mathbf{R}$ & Multiple & 0 & 6.0 & Brunswik \\
\hline 6 & $33^{*}$ & $\mathbf{M}$ & L & Multiple & 0 & 7.0 & McKee-Farrar \\
\hline 7 & 66 & $\mathbf{M}$ & $\mathbf{R}$ & $\begin{array}{l}\text { Solitary } \\
\text { distal }\end{array}$ & $4 \dagger$ & 4.8 & Brunswik \\
\hline 8 & 36 & $\mathbf{F}$ & $\mathbf{L}$ & $\begin{array}{l}\text { Solitary } \\
\text { distal }\end{array}$ & 0 & 9.5 & Brunswik \\
\hline 9 & 56 & $F$ & L & Multiple & 7 & 9.0 & Brunswik \\
\hline 10 & 68 & $\mathbf{M}$ & L & $\begin{array}{l}\text { Solitary } \\
\text { distal }\end{array}$ & $4 \dagger$ & 5.0 & Lubinus \\
\hline 11 & 78 & $\mathbf{M}$ & $\mathbf{R}$ & Multiple & 0 & 2.0 & Lubinus \\
\hline 12 & 49 & $\mathbf{M}$ & $\mathbf{R}$ & Multiple & 23 & 12.5 & $\begin{array}{l}\text { Austin-Moore } \\
\text { (hemiprosthesis) }\end{array}$ \\
\hline 13 & 40 & $F$ & $\mathbf{R}$ & Multiple & 7 & 4.5 & Legrange-Letournel \\
\hline 14 & 52 & $\mathbf{M}$ & L & Multiple & $7+$ & 9.0 & Brunswik \\
\hline 15 & 60 & $\mathbf{M}$ & $\mathbf{L}$ & Multiple & 0 & 6.0 & Lubinus \\
\hline 16 & 64 & $\mathbf{M}$ & L & Multiple & $0 \dagger$ & 2.0 & McKee-Farrar \\
\hline
\end{tabular}

* the patient had tuberculous coxitis in childhood (see text) $\nmid 2^{\circ}$ to $3^{\circ}$ varus tilt

hips and single in three. Two hips showed a solitary granuloma around the lower part of the stem, and in one there was a solitary granuloma in the region of the lesser trochanter (Table II). In one exceptional case there was definite granulomatosis around the acetabular part of the prosthesis (Figs 5 and 6). All the patients had normal ESR and CRP levels.

Revision with the uncemented Lord total hip was performed on average 9.4 years (3.9 to 13.8) after the primary hip replacement; at that time the patients' average age was 64 years (42 to 81$)$. In all except four cases, the revision included cancellous bone grafting of the femoral cavities (Table II).

We have focused on the bony consolidation around the new cementless implant, evaluating the outcome on average 3.5 years (2.0 to 6.0) after revision, using the Mayo hip score (Kavanagh and Fitzgerald 1985).

\section{RESULTS}

Routine bacterial cultures, taken at operation, were all negative. Histopathology of the granulomas showed collagen deposition, and a large number of histiocytes and giant cells, sometimes containing microscopic cement particles.
Radiographs showed that the bone around the prosthesis stem had consolidated to the same density as the surrounding bone, on average 16 months (12 to 28 ) after the revision. No case showed measurable sinking of the prosthesis or varus tilting. Even the largest granulomas, having been filled with massive cancellous bone grafts, had become totally consolidated. In the four cases where no cancellous bone had been transplanted, the original cavities had become filled with compact bone by 14 to 19 months after revision.

At follow-up the patients' mean total Mayo score was 91 points ( 78 to 100 ) (Table II), nine patients having an excellent result, five good and two fair. Eight patients were totally without pain and the remaining eight had only slight transient pain under stress.

\section{DISCUSSION}

It has been pointed out that aggressive granulomatosis in cemented replaced hips is a separate entity, differing clinically, histopathologically and radiographically from other types of prosthetic loosening. The cause of aggressive granulomatosis is still unclear. Acrylic cement is known to be relatively inert as long as there is sound fixation (Charnley 1979), but fragmentation of the cement 
Table II. Follow-up results after revision with uncemented Lord prosthesis at 2 to 6 years (average 3.5)

\begin{tabular}{|c|c|c|c|c|c|c|c|c|}
\hline \multirow[b]{3}{*}{ Case } & \multirow{3}{*}{$\begin{array}{l}\text { Radiographic } \\
\text { consolidation (mth) }\end{array}$} & \multirow{3}{*}{$\begin{array}{l}\text { Flexion } \\
\text { (degrees) }\end{array}$} & \multirow[b]{3}{*}{ Pain } & \multirow{3}{*}{$\begin{array}{l}\text { Shortening } \\
\text { (mm) }\end{array}$} & \multicolumn{4}{|c|}{ Mayo score } \\
\hline & & & & & \multicolumn{4}{|c|}{ Radiographic } \\
\hline & & & & & Function & Result & Total & Outcome \\
\hline 1 & 17 & 105 & Slight & 0 & 20 & 20 & 94 & Excellent \\
\hline $2^{*}$ & 13 & 90 & None & 0 & 20 & 18 & 98 & Excellent \\
\hline $3^{*}$ & 14 & 90 & None & 0 & 20 & 20 & 100 & Excellent \\
\hline 4 & 17 & 80 & Slight & 0 & 13 & 20 & 83 & Good \\
\hline 5 & 19 & 100 & None & 0 & 15 & 20 & 95 & Excellent \\
\hline 6 & 22 & 60 & Slight & 20 & 13 & 20 & 78 & Fair \\
\hline $7 *$ & 18 & 90 & None & 0 & 19 & 20 & 99 & Excellent \\
\hline 8 & 13 & 100 & Slight & 0 & 17 & 20 & 92 & Excellent \\
\hline 9 & 12 & 90 & Slight & 15 & 11 & 14 & 78 & Fair \\
\hline 10 & 12 & 90 & None & 0 & 15 & 16 & 89 & Good \\
\hline 11 & 13 & 110 & None & 0 & 20 & 20 & 100 & Excellent \\
\hline $12^{*}$ & 17 & 100 & None & 0 & 15 & 20 & 93 & Excellent \\
\hline 13 & 28 & 95 & None & 0 & 20 & 20 & 100 & Excellent \\
\hline 14 & 12 & 80 & Slight & 0 & 13 & 14 & 82 & Good \\
\hline 15 & 12 & 90 & Slight & 5 & 19 & 16 & 85 & Good \\
\hline 16 & 12 & 70 & Slight & 10 & 17 & 14 & 86 & Good \\
\hline
\end{tabular}

* no bone grafting

Case 2. Figure 5 - A 46-year-old man had total hip replacement with a Brunswik prosthesis for primary osteoarthritis. Ten years later there are multiple granulomas around the femoral stem of the cemented prosthesis, and, unusually, also around the acetabular component (arrows). Figure 6 - Eleven months after the revision, the hip is painless and the prosthesis well fixed. The radiographic granulomas are gradually disappearing.

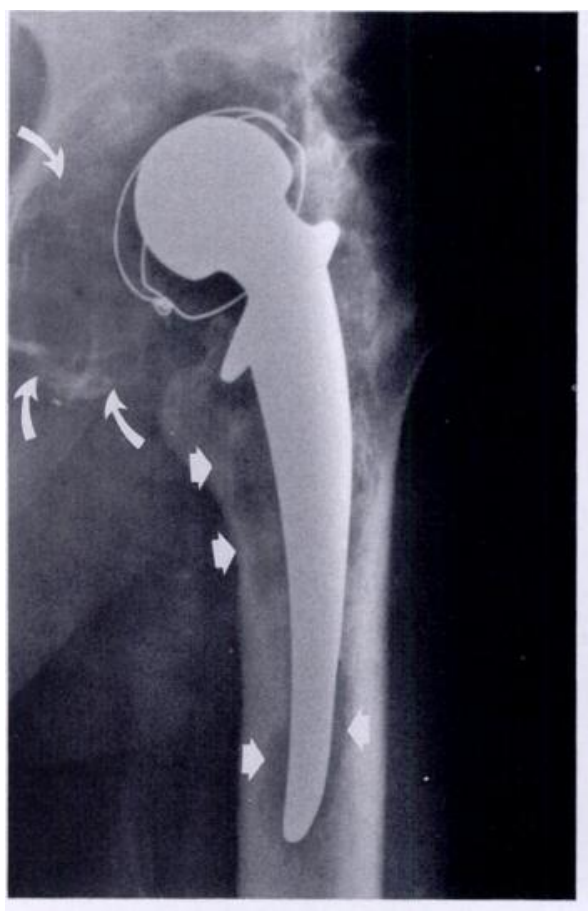

Fig. 5

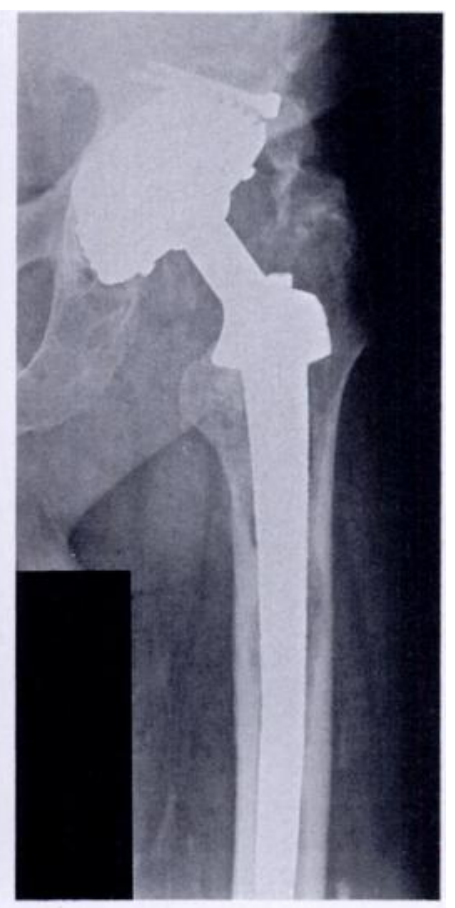

Fig. 6 
mantle and failure of fixation of the prosthesis have been suggested as possible reasons for granuloma formation (Harris et al 1976). The surprising fact that many of the prosthesis stems which are surrounded by large granulomas are found to be well fixed at revision operation is against this theory (Tallroth et al 1989).

The synovia-like biomembrane formed around polymethylmethacrylate cement has the capacity to produce prostaglandin $\mathrm{E}_{2}$ and collagenase; these may mediate the resorption of bone (Goldring et al 1983). Further, fragments of cement released at sites of prosthesis loosening can induce production of interleukin- 1 and tumour necrosis factor, which are also recognised inducers of bone resorption (Herman et al 1988).

Stress pain is the first clinical sign of aggressive granulomatosis, but by then the granulomas are sometimes already very large. Untreated large granulomas carry a risk of fracture around the prosthetic stem or even fracture of the implant. Our previous work has shown that most cases can be satisfactorily treated with revision and a new cemented total hip replacement but there is a risk of recurrence associated with catastrophic bone loss. The use of acrylic cement to fill a massive void is gradually being abandoned for both biological and mechanical reasons, commonly referred to as cement disease (Jones and Hungerford 1987). In contrast, recent work has indicated that revision with uncemented titanium stems induces osteogenetic activity. This can fill minor cavities; larger defects need cancellous bone grafting (Hungerford and Jones 1988; Lord et al 1988).

The results of our review suggest that aggressive granulomatosis in cemented replaced hips can be satisfactorily treated with a cementless revision prosthesis combined with cancellous bone grafting when the granulomas are large.

This study was financially supported by the Paulo Foundation, the Finska Läkaresällskapet Foundation and the Tampere Tuberculosis Foundation.

No other benefits in any form have been received or will be received from a commercial party related directly or indirectly to the subject of this article.

\section{REFERENCES}

Bell RS, Ha'eri GB, Goodman SB, Fornasier VL. Case report 246 : osteolysis of the ilium associated with a loose acetabular cup following total hip arthroplasty, secondary to foreign body reaction to polyethylene and methyl methacrylate. Skeletal Radiol 1983; 10:201-4.

Charnley J. Low friction arthroplasty of the hip: theory and practice. Berlin, etc: Springer-Verlag, 1979.

Goldring SR, Schiller AL, Roelke M, Rourke CM, O'Neill DA, Harris WH. The synovial-like membrane at the bone-cement interface in loose total hip replacements and its proposed role in bone lysis. $J$ Bone Joint Surg [ Am] 1983; 65-A :575-84.

Griffiths HJ, Burke J, Bonfiglio TA. Granulomatous pseudotumors in total joint replacement. Skeletal Radiol 1987; 16:146-52.

Harris WH, Schiller AL, Scholler JM, Freiberg RA, Scott R. Extensive localized bone resorption in the femur following total hip replacement. J Bone Joint Surg [ Am] 1976; 58-A :612-8.

Herman JH, Sowder WG, Appel AM, Hopson CN. PMMA cement implicated in IL-1, TNF and PGE 2 production. Rheumatology News International 1988; 16:3.
Hungerford DS, Jones LC. The rationale of cementless revision of cemented arthroplasty failures. Clin Orthop 1988; 235:12-24.

Jones LC, Hungerford DS. Cement disease. Clin Orthop 1987; 225: 192-206.

Kavanagh BF, Fitzgerald RH Jr. Clinical and roentgenographic assessment of the total hip arthroplasty: a new hip score. Clin Orthop 1985; 193:133-40.

Lord G, Marotte J-H, Guillamon J-L, Blanchard J-P. Cementless revisions of failed aseptic cemented and cementless total hip arthroplasties: 284 cases. Clin Orthop 1988; 235:67-74.

Reinus WR, Gilula LA, Kyriakos M, Kuhlman RE. Histiocytic reaction to hip arthroplasty. Radiology $1985 ; 155: 315-8$.

Scott WW Jr, Riley LH Jr, Dorfman HD. Focal lytic lesions associated with femoral stem loosening in total hip prosthesis. AJR 1985; $144: 977-82$.

Tallroth K, Eskola A, Santavirta S, Lindholm TS, Konttinen YT. Aggressive granulomatous lesions in hip arthroplasty. J Bone Joint Surg $[\mathrm{Br}] 1989 ; 71-\mathrm{B}: 571-5$. 